\title{
The use of a Tablet PC for instruction: a theoretical framework
}

\author{
Gerrit Stols \\ University of Pretoria, South Africa \\ gerrit.stols@up.ac.za
}

\begin{abstract}
This article is about my own journey and my reflections during my first month of using technology for instruction. The context was the use of a tablet PC and the possibilities that it creates for teaching mathematics to pre-calculus and calculus pre-service teaching students. This study attempts to understand, from the inside, the use computers for instruction, which is why the lecturer himself was also the principal researcher in this study. The advantage of using my own practice as a site for studying the processes of integrating technology into teaching is that it offers special possibilities for insight into and understanding of the thinking and emotions involved. This research may be seen as a special case of a qualitative case study. After three months of using technology for instructional purposes, I tried to make sense of my own journey by analysing my reflections using the Theory of Planned Behaviour as a theoretical framework. It was found that this theory, after some adaptations, might be used to clarify and understand my own use of technology for instruction.
\end{abstract}

\section{Introduction and rationale}

Huge amounts of money have been invested in equipping schools with computer-based technologies, but there is little evidence of the positive affect of these technologies on classroom practices or on student achievement (Wenglinsky, 1998; Zhao, Pugh, Sheldon \& Byers, 2002). Salomon (2005) describes the relationship between technology and education as an unhappy marriage. The understanding of the conditions under which teachers will use technology for instruction remains a research issue (Venkatesh \& Davis, 2000). Some researchers blame the technology, and some the teachers for not using technology. According to Cuban (2001, p. 152) in researching teachers' behaviour in using or not using technology, one needs to go beyond popular explanations that tend to blame teachers or the technology. Some of these reasons, such as the absence of computers, are trivial while others are complex and require more insight. The theoretical framework for the integration of instructional technology in the classroom is not well developed and more understanding is needed to understand how, when and under which conditions technology should be used for classroom instruction.

\section{Theoretical framework}

The prediction and understanding of human behaviour in general resides in the research field of social psychology. Much work has been done and different models exist for trying to predict and explain human behaviour. The question is whether these models can help me to understand my own preferences in using technology in my classrooms. In 1975 Icek Ajzen and Martin Fishbein developed a model that explains the relationship between attitude and behavioural intention. This model was later known as the Theory of Reasoned Action (TRA) and was used as a basis for many other theories. Ajzen realised that not all behaviour is under volitional control and in 1988 included perceived behavioural control as one of the three main factors that drives behaviour intention. This extension of the TRA is called the Theory of Planned Behaviour (TPB). The TPB explains human action and suggests that human action is guided by behavioural beliefs, normative beliefs and control beliefs. Together, these three factors will determine the behaviour intention, and hence in the end, also the behaviour, given a sufficient degree of actual control over 
the behaviour.

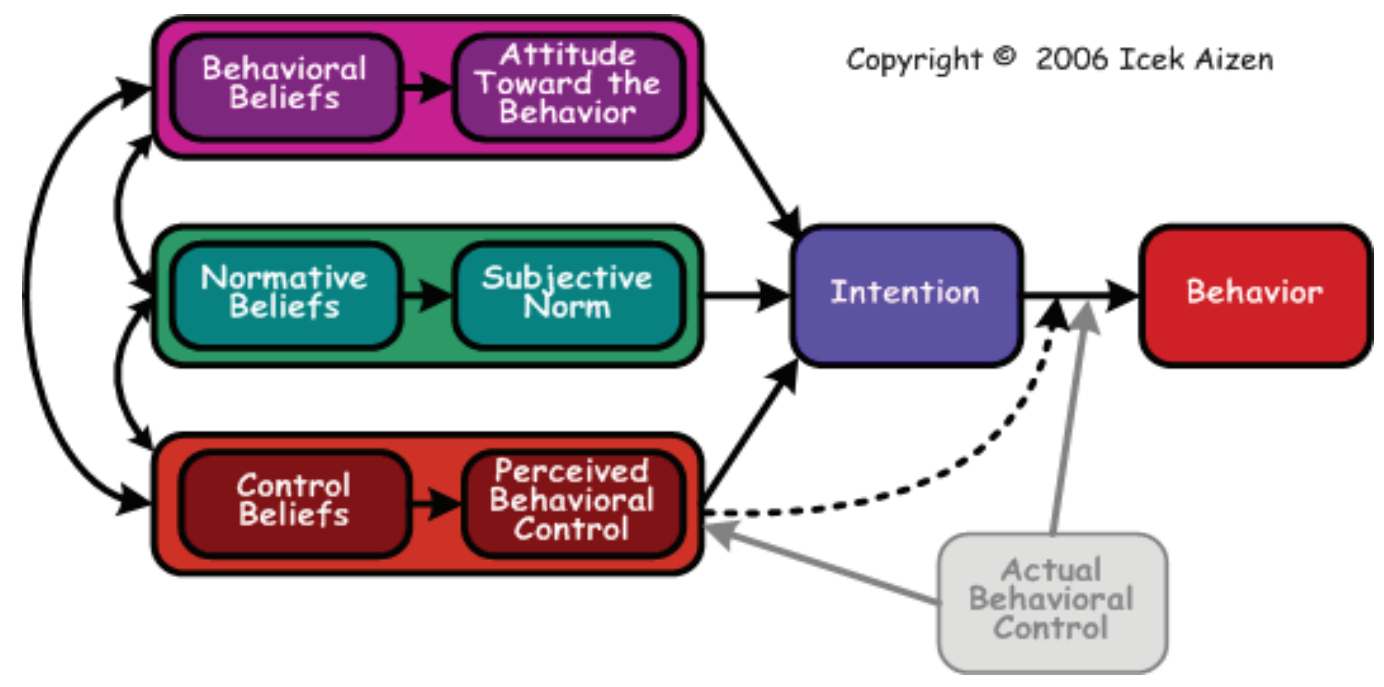

Figure 1: Theory of Planned Behaviour (TPB)

(Copied from Aizen's website: http://www.people.umass.edu/aizen/tpb.diag.html)

Ajzen (1991) explains that behavioural beliefs are the beliefs about the likely outcomes of behaviour and the corresponding judgements about these outcomes, while normative beliefs are about the expectations of other people and motivation to comply with their expectations. Control beliefs are about the presence of factors that may facilitate or impede performance of the behaviour and also the perceived power of these factors. These three considerations, respectively, will produce a positive or negative attitude towards the behaviour, and will result in perceived social pressure, and give rise to perceived behaviour control (Ajzen, 2006). Control factors include both internal factors and external factors. Internal factors are about skills, abilities and emotions while environmental factors are considered as external.

Information technology (IT) researchers have developed different models for studying the software utilisation choices of users. The Technology Acceptance Model (TAM) and the Theory of Innovation Diffusion (IDT) are used to determine the technology acceptance of users. These models can also be used to clarify behavioural beliefs in the context of the use of technology for instruction. In 1992 Davis and Bagozzi adapted the TRA to develop the Technology Acceptance Model (TAM) as an attempt to explain factors that influence users' acceptance of information technology systems.

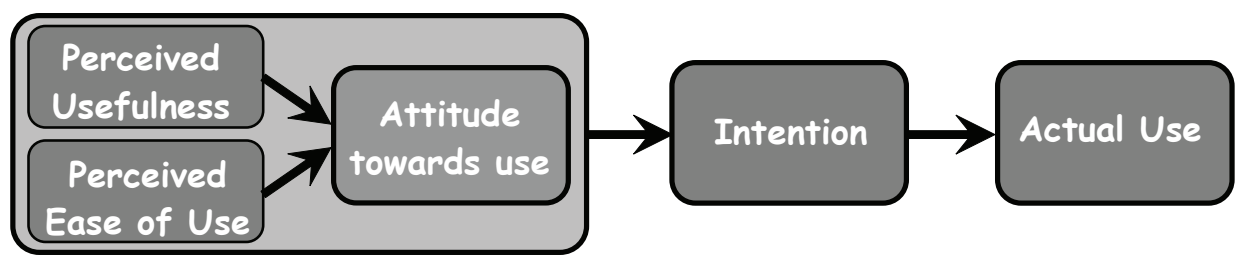

Figure 2: Technology Acceptance Model

TAM theorises that an individual's attitude towards technology and the behavioural intention to use IT are determined by the perceived usefulness and perceived ease of use of that specific 
technology (Venkatesh \& Davis, 2000) (see figure 2). Perceived usefulness is about the extent to which a person believes that using the system will enhance his or her job performance, while perceived ease of use is about a person's beliefs that using the specific technology will be free of effort (Davis, 1989, p. 320). Several researchers have replicated Davis's research and found perceived usefulness to be a strong determinant of user intentions:

Numerous empirical studies have found that TAM consistently explains a substantial proportion of the variance (typically about $40 \%$ ) in usage intentions and behavior... In 10 years, TAM has become well-established as a robust, powerful, and parsimonious model for predicting user acceptance (Venkatesh \& Davis, 2000, p. 186).

Sheppard, Hartwick and Warsaw (1988) found a correlation coefficient $(r)$ of 0.54 between behaviour intention and actual use within the field of consumer behaviour. Currently TAM is a well-established model and is widely accepted among researchers in the field of IT.

The Theory of Innovation Diffusion (IDT) adds another aspect to behavioural beliefs - the compatibility of the technology (Rogers, 1995). This model explains that the main characteristic that determines the acceptance and use of a technological innovation is the relative advantage, the compatibility and complexity of the innovation. There exists a great similarity between the variables of TAM and IDT: the relative advantage of the innovation of IDT is related to the perceived usefulness, while the complexity of the innovation of IDT is related to the perceived ease of use of TAM. However, TAM does not make provision for the compatibility of an innovation; that is, whether the innovation is consistent with existing values and past experiences of the user.

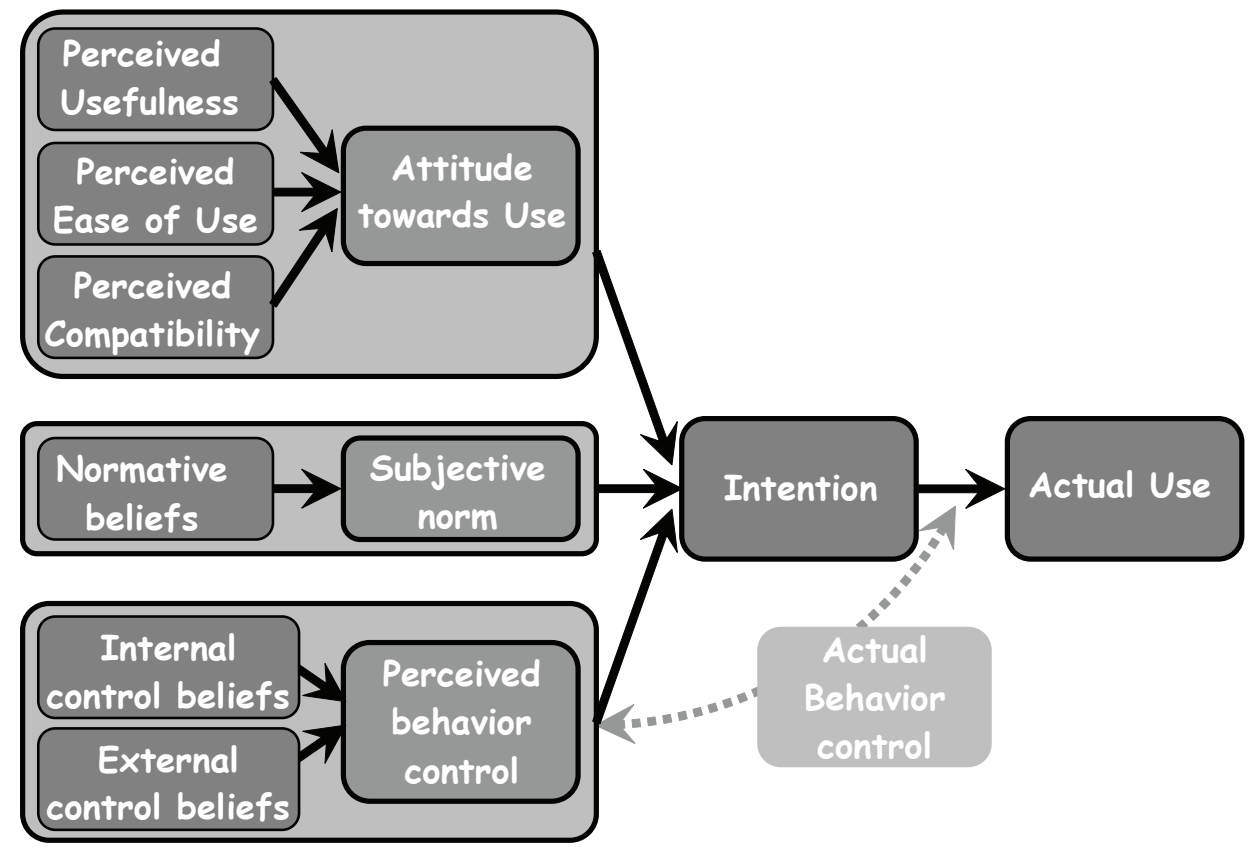

Figure 3: Theory for the Integration of Educational Technology (TIET)

I will refer to these combined models (see Figure 3) as the Theory for the Integration of Educational Technology (TIET) and use the model as a framework for analysing the reflections made after each teaching session during which technology was used for instruction. 


\section{Research objective}

A central goal of this study is to make sense of my own use of technology for instruction by reflecting on my own journey and analysing these reflections using the Theory for the Integration of Educational Technology (TIET).

\section{Contexts}

\section{Background}

I am a mathematics lecturer at the University of Pretoria (an urban university) in South Africa. I am responsible for two mathematics courses for pre-service teachers, namely pre-calculus and calculus. I am a technology enthusiast and fit into that category of teachers who use technology in general, but not for instruction. Analysing myself in terms of the six specific categories of instructional use of technology proposed by Russell, Bebell, O'Dwyer and O'Connor (2003, p. 297), I would say that I use technology for preparation, for recording grades and for e-mail, but not for instruction. I designed my own web pages for my courses and all my courses are on WebCT - which means that the students can access all the memos, study guides, transparencies and previous exam papers through the Internet. The lecture halls I use are not equipped with data projectors or sound systems. Only a chalkboard, an overhead projector (OHP) and screens are available.

\section{Kind of technology}

A tablet PC is a notebook computer which allows the user to operate it with a digital pen instead of a keyboard or mouse. Windows XP Tablet PC Edition is specially designed for a tablet PC. An Education Pack for Windows XP Tablet PC is included. This contains five programs that can help one to get organised. The programs are Ink Flash Cards, Equation Writer, Microsoft Office OneNote 2003, GoBinder Lite, and Hexic Deluxe for Tablet PC. Other programs installed include MS Office, Windows Journal, Sticky Notes, and Geometer's Sketchpad.

After some reading and discussion I decided that the most appropriate way for me to integrate technology into my mathematics content courses was to use a tablet PC. The reason for using a tablet PC as a basis for using technology for instruction was that it enables the user to react immediately to the situation, the level of understanding displayed, and the questions asked in the classroom (unlike a normal PowerPoint presentation). I do not need to type the mathematical equations but can write them down quickly. Everything that one normally does on transparencies and the chalkboard and more can be done on a tablet PC. Amongst other things, one can also

- $\quad$ play a video clip;

- generate memos of the homework questions using Solution Builder;

- draw graphs in Geometer's Sketchpad;

- create classroom notes using Windows Journal and immediately make them available to students via Bluetooth or by using a memory stick (the explanations that I would normally write on the chalkboard can even be printed).

\section{Research method}

I was the principal researcher in this study. The advantage of using my own practice as a site for studying the processes of integrating technology into teaching is that it offers special possibilities for insight into and understanding of the thinking and emotions of the teacher (or lecturer). Ball (2000, p. 366) explains the advantage of the teacher being the principle investigator of the research:

Looking from inside, they probe aspects of the enterprises of teaching and learning often invisible to outsiders. For example: What are the special anxieties and issues entailed in 
changing one's practice? ... What struggles inhere in trying to unlearn pedagogical habits and to learn to teach differently?

First person research where the researcher himself or herself is the object of the study is generative. Although working from the inside, as a lecturer and teacher and also as the principal researcher, has its advantages, there are some pitfalls as well. I cannot and do not wish to claim that the research is objective. I can, however, claim that my reflections were honest.

This research can be seen as a special case of a qualitative case study: "It strives to illuminate a broader point, probe a theoretical issue, develop an argument or framework" (Ball, 2000, p. 374). One of the inside approaches to inquiry in teaching is reflection. "'Reflection' in and on teaching has as its primary goal to heighten deliberation in and about practice" (Ball, 2000, p. 366). During and after each class I reflected on what had happened to me and about the nature of the thinking and reasoning behind my decisions. After three months of using technology for instructional purposes, I tried to make sense of my own reflections by clustering the reflections into themes suggested by the TIET model (see Figure 3). The categories or themes are perceived usefulness, perceived ease of use, perceived compatibility, normative beliefs, internal control beliefs, and external control beliefs. The model was developed six months after the reflections, and therefore did not bias the reflections made.

\section{Results and discussion}

It was possible to cluster all the reflections under one of the above-mentioned categories as suggested by TIET (see figure 3 ).

\section{Perceived usefulness and perceived ease of use}

Davis (1989) defines perceived usefulness as "the degree to which a person believes that using a particular system would enhance his or her job performance". In the context of this study the perceived usefulness is the degree to which I believe that using a tablet PC and its applications would enhance the teaching and/or learning process. Although my teaching approach is a more traditional lecturing approach, my measure of successful teaching is student understanding. This was also how I evaluate the usefulness of using the tablet PC:

The students understood the work and successfully completed their homework during the 2-hour class.

BUT the harder work definitely pays off in terms of students' attention and understanding.

After the video I explained the whole idea of determining the area under a curve and it was nice to be able to work on a previously typed graph with the tablet pen in different colours. I would not have been able to give such an effective class without the use of technology. I created the memos with the solution builder and we discussed and marked the questions.

An important factor for me was that the students had to perceive the technology as useful for enhancing their own understanding:

I am thinking of giving the students a questionnaire on the way they prefer the teaching and the reasons why. I am at this stage willing to make the final decision about the use of technology on the basis of the students'feedback.

After class we had a brief discussion about the way of teaching that the students prefer. They prefer the use of the tablet instead of the chalkboard by far. The reason according to them is that they understand the work more easily and faster. 
I perceive the publication of class notes also to be a useful feature because of the positive feedback from the students.

The program [Windows Journal] will enable me to save the file and publish it on WebCT in a pdfformat. I am looking forward to the next class to use this application of Microsoft.

The students find it useful because whenever a student misses an answer or notes they can download them from the internet after class. The advantage is that the lecturer does not erase the traces of the discussion. Some of the students in fact printed all the class notes.

From the reflections it is also clear that perceived usefulness and perceived ease of use are measured in terms of existing teaching practices:

The only frustration was that I cannot show movement on the tablet in the same way that I was used to doing on the chalkboard. We were doing the Euclidian algorithm and synthetic division. I wanted to show them how to multiply the quotient by the divisor and add the remainder to be able to give you the dividend. It is also the comparison between long division and synthetic division where I felt that I needed the movement from the one to the other. I decided to circle the compared values using different coloured ink. I am not sure if it has the same effect and impact as the movement with the chalk. It forced me to use better language and to revise the terminology.

Four weeks later:

The use of the highlighter helped me a lot to make up for the lack of the ability to show movement.

The problem is, however, that if the perceived ease of use is measured in terms of current teaching practices, it will be compared to the ease of using the chalkboard and the OHP, which are extremely easy to use. If the use of technology is not perceived as useful enough to make the effort of using it worthwhile, it will not be used. This was highlighted by my reflections in the third week of using technology:

I do not think that the gain in understanding, if any, by using the tablet PC makes the effort of using it worthwhile.

From this reflection both perceived usefulness and ease of use played a critical role in the decision-making process involved in technology use in the classroom. Cuban (2001, p.122) explains: "Since the nineteenth century, chalk and blackboard, pens, pencils, and textbooks have proven themselves over and over again to be reliable and useful classroom technologies." Teaching is already a complex task; teachers do not have the time and energy to waste on complex technological systems. This was also clear from my own frustration:

The content was difficult to explain. I cannot take the stress of struggling with the tablet as well.

It is difficult to discriminate between usefulness and perceived ease of use because of the interplay between the two constructs. An example of the interplay can be seen from the following reflection in the third week of using technology:

... the fact that they provide a video CD with the textbook with somebody explaining the examples in the textbook, and that the textbook providers (Calculus by Stewart) also supply a CD that builds the solution of all the exercises in the textbook. This CD creates a pdf file of the solution that I cut and paste (using the snipping tool of the tablet PC) into Word where I can write with the tablet pen. In short the publishers of the textbook make it really easy 
to integrate technology into my teaching and at the end that helped me to decide not to use transparencies any more but rather use the tablet $P C$.

Textbook publishers have a major part to play in enhancing the perceived usefulness and ease of use. I used textbooks from the same publisher for the teaching of the calculus and pre-calculus courses. With the calculus textbook I received a pdf solution generator for all of the exercises in the textbook and a CD with video clips of explanations for some of the examples. This was not the case with the pre-calculus book. The difference this can make can be seen from the previous and the following reflections:

The publishers of the pre-calculus book do not make it easy to integrate technology into my teaching. They do not provide any Electronic media. I have to scan the solutions from the solution manual to PDF files (or ask my wife to do it with an industrial scanner). And what makes matters worse is that the publishers of the pre-calculus book have replaced this edition (4th edition of 2002) of the textbook. This does not make the effort of converting the hard copies to electronic format worth the while for this year-maybe next year. It is just much easier to make transparencies of the solutions and examples and explain them using the OHP and the chalkboard.

A real problem is the time it takes to prepare properly. Using technology requires better preparation and that requires more time:

My preparation was perfect-I chose a few video clips of examples and prepared a Word file with the memos of all the class work questions.

BUT the harder work definitely pays off in terms of students' attention and understanding.

After two weeks of integrating technology into my teaching I believe that it requires more work and proper preparation. You cannot integrate technology without planning precisely what you want to do, how you are going to do it, and when.

Another factor that influences the perceived ease of use of technology is the reliability of the technology (Cuban, 2001). A teacher cannot, during classroom instruction, afford an operating system that crashes. The cost in terms of teaching time and professional image is just too high. The unreliability of technology was also a real concern in my case.

I started the class with a video clip from one of the examples from the CD that comes with the textbook. I do not know what went wrong, but the computer stalled and I had to reboot the computer, after another 5 minutes

I could not, however, find a way to wake the PC if it went into sleep mode, using only the pen and the screen. It also happened when I wanted to draw circles in Word. What I normally do is to hold in the shift key and to drag a perfect circle with the mouse (if you do not use the shift key it can look like an egg).

After three weeks of using technology I got used to setting up the tablet PC and the data projector, but it sometimes happened that everything was not in place by the time that the class was to start:

I underestimated the setup time (arrived in class 3 minutes before the students) and started 5 minutes late because the tablet PC has to start and the projector must be plugged in.

After four weeks of using the tablet PC I started feeling more in control and had worked out how to prevent or overcome the majority of the previously unexpected technological problems: 
I am now used to the 5 minutes spent setting up the projector and the tablet. The technological surprises are now under control. Everything went extremely well and I felt good about the class

The standard software provided with the tablet PC, for example Windows Journal, was userfriendly:

The explanation and discussion went well. I found it easy to choose the different pens, colours and sometimes used the felt tip. The students started with the next exercise and continued without any mayor problems.

In summary, the use of the tablet PC takes more time and effort in the beginning compared to a traditional chalkboard approach. But in the long run, I believe it will save time and that using the videos and other software will enhance student learning and understanding. Looking at the reflections, clear patterns emerge that can be explained in terms of perceived ease of use and perceived usefulness. As my use of technology progressed I decided to use different equipment for different uses:

For my $1^{\text {st }}$ year pre-calculus class today I decided to use the OHP for the solutions and the tablet PC for explanations. It worked extremely well. I do not know why I actually tried to use the tablet PC only. The combination of the two worked fine.

I never thought about the usefulness in terms of student achievement, but just what the students perceived as useful in terms of understanding and knowledge gain.

\section{Perceived compatibility with existing practices}

I decided on the use of a Tablet PC with all its applications because I wanted to sustain, support and enhance my existing teaching practices (see remarks about the choice of technology in the section on the context). I had not anticipated the fact that it would cause so many disturbances. My first class was a revelation because there were so many decisions to make and all of them had implications:

It was my first class today. I went to class 5 minutes before the class started. I had to make quick decisions on where to put the tablet PC and the projector. The first decision was: Must I use the side OHP projector board or am I going to use the big screen that comes from the roof in front of the green chalkboard? This was an important decision because it would prevent me from using the chalkboard. But I decided to use it because of the size, but it made me feel uncomfortable - no chalkboard. For the image to be large enough I had to put the projector on the table in the first row where the students were sitting and the tablet on the lecturers' desk. I feel comfortable with the tablet because this was always my base from where I conduct all my teaching. This is the centre of the classroom. I am used to putting my textbook, notes and chalk ... around the lecturers table.

I moved the tablet near the projector and put it on a normal table (low - that was the only table available). I was not the centre of teaching activities any more.

I chose the blue pen from the tablet options and started to write. I was not sure if it was visible or clear enough for the students. Therefore I turned around and was relieved to see that everything looked quite OK. I proceeded with more confidence, but realised that I was not the centre of the teaching activities anymore. I have to sit to be able to write on the tablet and what made it worse was the fact that I had to bend over the tablet to see my own writing on the screen. Absolutely no eye contact with my students. That felt bad-firstly I am not in 
the centre, secondly I have to sit and now even no eye contact. It seems that everything went OK without having me in the centre spotlight.

The pre-calculus class consisted of 72 students and the calculus class only 10 students. Depending on the class size sitting down teaching made me feels uncomfortable:

The calculus class is a small class and I felt comfortable.

Because of the size of the calculus class (only 10 students) I did not feel uncomfortable explaining on the tablet while I am sitting down.

I totally under-estimated the "distance" between my prior teaching practices and the "new" practices required by the tablet PC. Zhao et al. (2002) explain that the distance is the degree to which an innovation differs from the prior educational practices of the teacher and that it will determine partly the success of the innovation.

\section{Normative beliefs}

The role and the possible impact of perceived ease of use of technology for instruction were influenced by the fact that I received a grant to do this research. This put extra pressure on me to master and continue using the tablet PC in my class. I do not know if I would otherwise have continued after the third week in using the tablet PC.

\section{Perceived behavioural control}

Perceived behavioural control is about the presence of factors that may facilitate or impede performance of the behaviour, and the perceived power of these factors (Ajzen, 2006). In the context of this article perceived behavioural control can be seen as factors influencing the extent to which I feel able to use technology in the classroom. Control factors include both internal factors and external factors. Internal factors are about skills, abilities, and emotions while environmental factors are external, like the available infra-structure.

Technology proficiency is an internal factor that can influence the perceived ease of use and the perceived usefulness of technology. If I had not been able to solve some of the unanticipated problems I would not have perceived the tablet PC as useful. I would describe myself as a highly computer-literate technology enthusiast. I use technology on a daily basis for preparation, for recording grades, for e-mail, and designing web pages. Before I used the tablet PC in class I made the following comment in my reflection:

I feel really comfortable with the tablet and am ready to use it in my class. I spent about 10 hours exploring, using and discovering all the different features and was really excited about all the possibilities and features.

I was also able to sort out the technological problems by myself. After the third week I commented:

I am now used to the 5 minutes spent setting up the projector and the tablet. The technological surprises are now under control. Everything went extremely well and I felt good about the class.

The importance of technological knowledge becomes even more important if things do not go as planned. If the technology does not respond as expected an even higher level of computer knowledge and skills is needed. This has already been discussed in the section on the perceived ease of use. It is therefore also clear that perceived ease of use and perceived behavioural control are interrelated. 
Using technology requires a certain comfort level with the appropriate content knowledge and the pedagogical content knowledge. This may be seen from the following reflection:

I did not prepare well enough for my class. It is a large class (about 60 students). Everything went wrong; I came in a few minutes late for my class. I did not feel comfortable - it was difficult work to explain and to understand and I decided that I was not going to use technology but instead felt more comfortable using the chalkboard to explain. If something is difficult to explain I prefer to use the chalkboard. It is enough not to feel confident about the content; I cannot take the stress of struggling with the tablet as well.

This may be the reason why more experienced teachers report using technology more often in the classroom in comparison to new teachers. Russell et al. (2003, p. 308) believe that the first few years of teaching are already so challenging, in that teachers have to develop behaviour management techniques and become familiar with the curriculum, that they do not have time to explore ways to integrate technology into their classroom practice.

External control beliefs in my context were the dependence on technological resources beyond my own control. Zhao et al. (2002) found that the innovations that require the "cooperation, participation, or support of people" not under the teacher's authority were most successful. If a teacher required significant amounts of technology beyond his/her immediate control the use of technology is considered highly dependent (Zhao et al., 2002). This is why I decided to use a tablet PC. I applied for funding to buy the tablet PC and booked our departmental data projector for the all my classes in advance. This was important because the lecture hall that I used was not equipped with a data projector; just a chalkboard, an overhead projector (OHP) and screens.

Our department has one projector between the 12 of us. I book the projector for all my classes for the half year in advanced. The one projector between the 12 of us does not seem to be a problem.

However, everything did not go smoothly. I was not able to use the data projector during week 3 because it was locked in the departmental safe and there was something wrong with the lock.

\section{Conclusion}

This research provides some insight into and understanding of the difficult and complicated process of using technology for instruction, and it explains this use from an insider's point of view. The TIET model (see figure 3 ) helped me to understand my own actions and decisions. The constructs of this model were used to organise and cluster the reflections and also provided a framework for giving insight into what it takes to use technology for instruction, as the use of technology is a complex process. Two determinants are crucial to the understanding of my usage of technology for instruction: whether I perceive it as useful for teaching and learning (i.e. if it increases the learners' understanding of the content or concepts) and whether I perceive it as requiring comparatively little effort. The perceived increase in understanding (gain), however, must be of such an order that it will make the effort of using the technology worthwhile. In the end the perceived usefulness outweighs the perceived ease of use although perceived usefulness is partly determined by perceived ease of use. The perceived ease-of-use did not prompt me to use technology but sometimes prevented me from using technology. Although it was somewhat tedious to arrange and set up the tablet PC before each class, I was willing to do this if I believed that it would have a positive impact on learning. The use of technology for instruction in my JWS220 Calculus class was easy and effective, but not in my JWS120 pre-calculus class. I used GSP, video clips with examples (included in the textbook), and Solution Builder (provided by the 
publisher of the textbook) during my calculus classes. These are easy to use and I perceived them as powerful tools for helping the students to understand the work. On the other hand, however, the publishers of the pre-calculus book did not make it easy to integrate technology into my teaching. I could have achieved the same level of student understanding using the chalkboard and OHP without the extra technological effort.

\section{Behaviour after 1 year}

After one year I still use the tablet PC on a daily basis for all my lectures. I have found ways to enhance the usefulness of the tablet PC in my instruction and have discovered that I can export my class notes from Windows Journal to html and publish them directly after the class on the internet for the students to download. In short, I have found ways to increase the perceived usefulness and to make teaching more efficient and the content more understandable for the student. The operating system of the computer still crashes now and then but apart from that, there are no technological surprises any more. I am now in the process of upgrading the RAM and hope that this will prevent the crashes.

In order to return to standing while teaching instead of sitting at a table where my laptop can be connected, I am looking for funding to use more advanced (wireless) equipment. A Bluetooth or network-enabled data projector will obviate the awkwardness of teaching while seated.

The students have a very positive attitude towards my use of technology and prefer that I use the tablet PC in class. Some of my colleagues, encouraged by the positive student reports, are also interested in using a tablet PC in their classes. It seems, however, that the need to use a tablet PC is not urgent enough for them to try to make a plan to find funding or to fund such purchase from their own pockets.

\section{References}

Ajzen, I. (1991). The theory of planned behaviour. Organizational Behavior and Human Decision Processes, 50(2), 179-211.

Aizen, I. (2006). Theory of Planned Behavior. Available online at: http://www.people. umass.edu/aizen/tpb.diag.html (accessed 12 May 2007).

Ball, D. L. (2000). Working on the inside: Using one's own practice as a site for studying mathematics teaching and learning, in: A. Kelly \& R. Lesh (Eds), Handbook of research design in mathematics and science education. Dordrecht: Kluwer.

Becker, H. J. (2000). Findings from the teaching, learning, and computer survey: Is Larry Cuban right? Education Policy Analysis Archives, 8(51). Available online at: $\quad$ www. epaa.asu.edu/epaa/v8n51/ (accessed 13 June 2006).

Becker, H.J., (2001). How are teachers using computers in instruction? Paper presented at the 2001 Meetings of the American Educational Research Association, University of California, Irvine, April, 2001 Available online at: www.crito.uci.edu/tlc/ FINDINGS/special3/ (accessed 21 April 2007).

Cuban, L. (2001). Oversold and underused computers in the classroom. London: Harvard University Press.

Davis, F. D. (1989). Perceived usefulness, perceived ease of use, and user acceptance of information technology, MIS Quarterly, 13(3), 319-340. 
Fishbein, M., \& Ajzen, I. (1975). Belief, attitude, intention, and behavior: An introduction to theory and research. Reading, MA: Addison-Wesley.

Mishra, P. \& Koehler, M. J. (2006). Technological pedagogical content knowledge: A framework for teacher knowledge. Teachers College Record, 108(6), 1017-1054

Rogers, EM. (1995). Diffusion of innovations. New York: Free Press.

Russell, M., Bebell, D., O’Dwyer, L. \& O’Connor, K. (2003). Examining teacher technology use: Implications for preservice and inservice teacher preparation, Journal of Teacher Education, 54(4), 297-310.

Salomon, G. (2005). Preface, in: C. Vrasidas \& G.V. Glass (Eds) Preparing teachers to teach with technology: Current perspectives on applied information technologies. Greenwich: Information Age Publishers.

Sheppard, B. H., Hartwick, J. \& Warsaw, P. R. (1988). The theory of reasoned action: A metaanalysis of past research with recommendation for modifications and future research. Journal of Consumer Research, 15, 325-343.

Venkatesh, V. \& Davis, F. D. (2000). A theoretical extension of the technology acceptance model: Four longitudinal field studies, Management Science, 46(2), 186-204.

Wenglinsky, H. (1998). Does it compute? The relationship between educational technology and student achievement in mathematics. Princeton, Educational Testing Service.

Zhao, Y. \& Cziko, G. A. (2001). Teacher adoption of technology: A perceptual control theory perspective Journal of Technology and Teacher Education, 9(1), 5-30.

Zhao, Y., Pugh, K., Sheldon, S. \& Byers, J. (2002). Conditions for classroom technology innovations: Executive summary. Teachers College Record, 104 (3), 482-515. 